\title{
Mechanical Properties and Energy Dissipation of Sandstone under Cyclic Loading-Unloading
}

\author{
Shoudong Xie $\mathbb{D}^{1,2,3}$ Chang Su ${ }^{1},{ }^{1}$ Ying Xu ${ }^{1},{ }^{1,2}$ Qianqian Wang, ${ }^{1,2}$ Jian Wang, \\ and Zixiang Xia ${ }^{4}$ \\ ${ }^{1}$ State Key Laboratory of Mining Response and Disaster Prevention and Control in Deep Coal Mines, \\ Anhui University of Science and Technology, Huainan, Anhui 232001, China \\ ${ }^{2}$ School of Civil Engineering and Architecture, Anhui University of Science and Technology, Huainan, Anhui 232001, China \\ ${ }^{3}$ Hongda Blasting Engineering Group Co., Ltd., Changsha, Hunan 410011, China \\ ${ }^{4}$ Pingliang Wuju Coal Industry Co., Ltd., Pingliang, Gansu 744200, China
}

Correspondence should be addressed to Chang Su; suchanguser@126.com

Received 24 June 2021; Accepted 3 August 2021; Published 9 August 2021

Academic Editor: Xiao Wang

Copyright (c) 2021 Shoudong Xie et al. This is an open access article distributed under the Creative Commons Attribution License, which permits unrestricted use, distribution, and reproduction in any medium, provided the original work is properly cited.

\begin{abstract}
For the bearing rock in geotechnical engineering, it is frequently affected by external loads. This paper adopted different upper limits of stress to carry out cyclic loading-unloading on the sandstone specimens to make them in different damage degrees and analyzed the mechanical mechanism of the damaged sandstone under different stresses. Then, the strength change and energy evolution of sandstone with different damage degrees were analyzed, and the damage of the loaded sandstone was quantitatively characterized. The experimental results showed that the strength and plastic deformation of sandstone after cyclic loading-unloading with different upper-stress limits gradually decreased with the increase of the upper-stress limit. In the loading-unloading stages of cyclic loadingunloading, the elastic modulus increased with the increase of the upper-stress limit. In general, as the number of cycles increased, the total strain energy density and elastic deformation energy density gradually increased, and as the upper-stress limit increased, both of them also increased. The damage factor of sandstone after cyclic loading-unloading, which was characterized by dissipated energy, increased in an $S$-shape with the increase of the upper-stress limit, and the growth rate first increased and then decreased.
\end{abstract}

\section{Introduction}

As the most common load-bearing medium, rock widely exists in geotechnical engineering, such as mine surrounding rock tunnels and underground protection projects [1-7]. Affected by human excavation activities, rock masses are in varying degrees of damage under the disturbance of cyclic loads with different upper-stress limits [8-10]. The superimposition of damage leads to the evolution of the rock mass from the rupture of the internal mesostructure to the external macroscopic deformation and destruction. The bearing capacity of the damaged rock and the deformation capacity of resisting load is weaker than that of the original rock, which brings major hidden dangers to the safety of construction personnel [11]. In the indoor experiment, the method of cyclic loading-unloading is mainly used to analyze the mechanical properties and damage degree of the loaded rock, which provides some references for the safety production and stability analysis of the project site [12].

From the theory of rock damage mechanics, it can be known that the damage of the rock actually deteriorates the internal structure under the action of external load and leads to the process of weakening the bearing capacity of the rock mass [13]. Accumulation of rock mass damage will lead to a decline in its integrity and load-bearing capacity, as well as unreliable stability [14]. For the evolution process of rock mass damage, many scholars have also reached specific conclusions [13, 15-17], but the damage evolution of different rocks under external loads is not consistent. It shows that the damage of the loaded rock does not depend on the external loading path only but is also closely related to the mechanical response of the rock mass [18]. The study of the 
mechanical response of the loaded rock mass is basic research to study the evolution law of rock damage, the damage constitutive relationship, and the strength change of the damaged rock mass. Therefore, in order to analyze the damage of the loaded rock mass further, it is necessary to establish a reasonable damage constitutive equation from the perspective of damage mechanics and further explore the evolution law of rock mass damage. For the characterization of the damage of the loaded rock, many scholars have put forward a very valuable method, hoping to obtain the rock damage constitutive equation based on different damage variables, in order to reflect the damage characteristics and strength change law of the loaded rock [19-21].

The mechanical properties of rock under cyclic loading include a series of issues such as strength change [22, 23], deformation [24, 25], and energy evolution [26, 27]. After the cyclic loading, the internal microstructure of the rock has deteriorated, such as the primary pores are compacted and closed, the cemented matrix cracks and the cracks propagate, and even the main crack propagates and penetrates, and the rock is damaged and unstable [28]. As the rock is not damaged or destabilized, it still has the bearing capacity, but the bearing capacity is reduced compared with the original rock $[29,30]$. The extent of the reduction is related to the maximum stress value, the loading rate, and the number of cycles [31]. When the rock surface is without significant deformation and cracks, affecting the deterioration of the internal structure of rock-on-rock damage, it cannot be intuitively grasped. Many scholars analyze the damage degree of the rock under cyclic loading based on the energy evolution of the loaded rock during the cyclic loadingunloading process $[32,33]$. By analyzing the strength change and energy evolution of the rock under cyclic loading, it has an important reference value for the analysis of the damage and stability of the loaded rock.

Aiming at the problem of damage of loaded rock, this paper adopted cyclic loading-unloading with a different upper-stress limit to make the rock in different degree of damage state and analyzed the strength change, energy evolution, and damage degree of damaged rock. First, determine the uniaxial compressive strength $\sigma$ of the rock. Then, the upper-stress limits of $0.2 \sigma, 0.4 \sigma, 0.6 \sigma$, and $0.8 \sigma$ were cyclically acted on the sandstone to make them in different degrees of damage. Finally, the strength change and energy evolution of damaged rock after cyclic loading with different upper stresses were analyzed, and the damage of rock after cyclic loading with different upper stresses was further explored.

\section{Experiment}

The rock used in this experiment was taken from the rocky slope of Cezi Island, Zhoushan City, China, and the lithology was sandstone. According to the standards of the International Society for Rock Mechanics, after cutting and grinding indoors, a cylindrical sample with a size of $\Phi$ $50 \mathrm{~mm} * h 100 \mathrm{~mm}$ was prepared. The flatness error of both ends of the rock should be controlled below $0.01 \mathrm{~mm}$, and the nonparallelism of the two ends should be less than
$0.05 \mathrm{~mm}$. The partially processed rock samples are shown in Figure 1.

The loading device of this experiment adopted the rock mechanics test system (RMT-150C) developed by the Wuhan Institute of Geotechnical Engineering, Chinese Academy of Sciences, as shown in Figure 2. First, a uniaxial compressive test was carried out on the processed sandstone specimen to determine the uniaxial compressive strength $\sigma$ of the sandstone specimen. Then, based on the compressive strength of the rock, cyclic loadingunloading experiments with different upper-stress limits were carried out to make the sandstone in different degrees of damage. The cyclic loading was carried out in the way of equal upper-stress limit, and the number of cyclic loading-unloading was 7 . The upper-stress limits used in this experiment were $0.2 \sigma, 0.4 \sigma, 0.6 \sigma$, and $0.8 \sigma$, and the loading rate was $500 \mathrm{~N} / \mathrm{s}$. Finally, the strength change, elastic modulus change, and energy evolution of the damaged sandstone after different cyclic static load upperstress limits were analyzed, and the damage of the rock after cyclic loading-unloading was studied.

\section{Experimental Results and Analysis}

The stress-strain curve of sandstone under uniaxial load is shown in Figure 3. By analyzing the strength of sandstone under uniaxial load, it can be known that the uniaxial compressive strength of the sandstone specimen used in this test was $61.14 \mathrm{MPa}$. Based on the measured uniaxial compressive strength of the sandstones, the upper-stress limits of 12.23 $\mathrm{MPa}$, 24.26 $\mathrm{MPa}, \quad 36.68 \mathrm{MPa}$, and $48.91 \mathrm{MPa}$ were taken in sequence to act on the sandstone specimens to make them in different degrees of damage. The stress-strain curve of loading is shown in Figure 4.

According to the experimental results, the plastic deformation of sandstone increased with the increase of the upper-stress limit. When the upper-stress limit was 12.23 MPa, $24.46 \mathrm{MPa}, 36.68 \mathrm{MPa}$, and $48.91 \mathrm{MPa}$, the plastic deformation was $0.0010,0.0015,0.0028$, and 0.0041 in sequence. This showed that with the increase of the upperstress limit, the irreversible, permanent deformation of the sandstone specimens after the cyclic loading-unloading action gradually increased, and the increase in 33\%, 64\%, and $76 \%$ took the upper-stress limit is $12.23 \mathrm{MPa}$ as a reference, the growth rate also gradually increased. At the same time, it also showed that the damage degree of sandstones after cyclic loading-unloading increases with the increase of the upper-stress limit, and the growth rate also gradually increased.

In the mechanical test of sandstone under uniaxial load, the strain curve of loaded sandstone was analyzed. With the action of load, the rock was finally compressed and destroyed. This macroscopic mechanical appearance was the qualitative change caused by the quantitative change of mesostructure. The change of microstructure in the whole process from loaded rock to failure was mainly composed of three parts: compaction and closure of primary pores, relative slip between gravels, and main fracture connection [34]. The compaction closure of primary pores mainly 


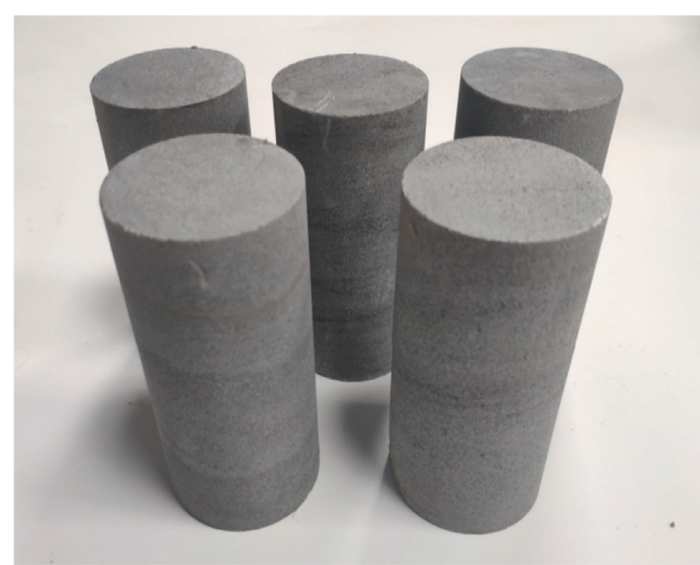

Figure 1: Partial sandstone samples.

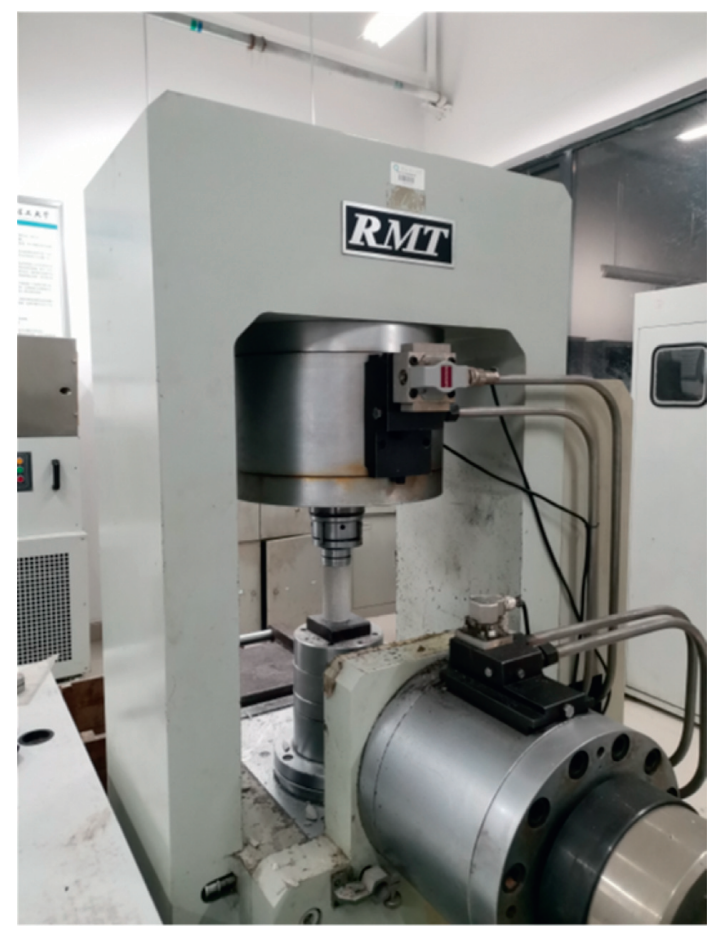

FIgURe 2: RMT-150C.

occurred in the initial compression stage of rock, and its deformation was nonlinear. The deformation caused by relative slip between gravels was irrecoverable, which usually occurred in the loading section of cyclic loading-unloading, and mainly in the initial loading stage. Influenced by diagenesis, there were primary pores and fractures with different sizes and densities in sandstone. In the initial loading stage, the primary fractures were easy to be compacted and closed, but the initial pores cannot be completely closed. The gravel around the pore would deform under the condition of continuous stress, and the increasing deformation would lead to the rock blocks between the contact surfaces cracking and fell off. This was the formation process of local deformation of the loaded rock, and the local deformation would cause the overall plastic deformation.

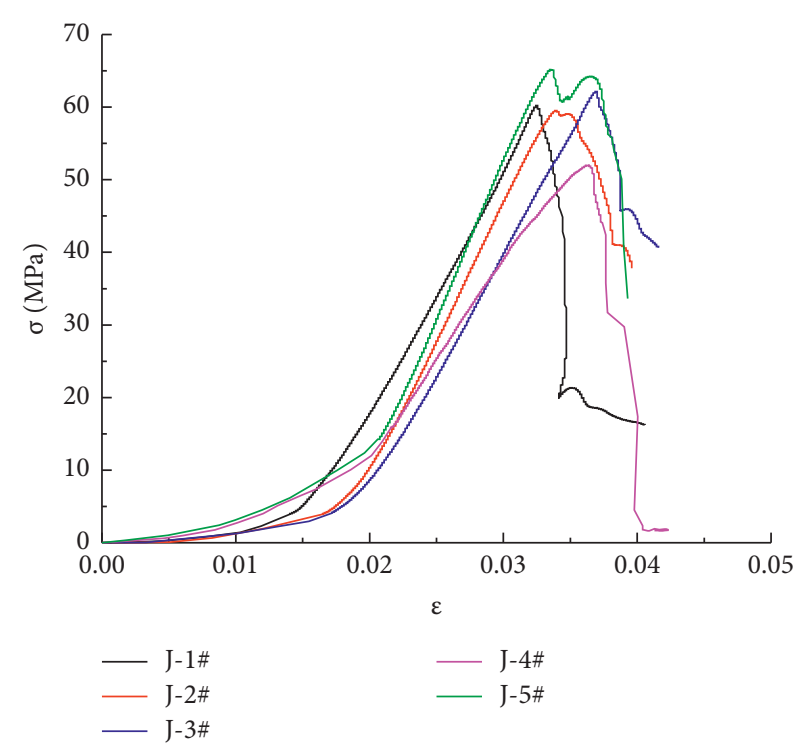

FIgURE 3: Stress-strain curve of sandstone under uniaxial loading.

The deformation of sandstone under uniaxial loading could be divided into the following stages: (1) Initial compaction stage: in this stage, the pores in sandstone were compacted and closed, and local irreversible deformation occurred, resulting in strength reduction. (2) Elastic deformation stage: the stress-strain curve was close to a straight line, and the loaded sandstone was close to an elastic body. (3) Microcrack propagation stage: with the continuous increase of load and gradually reaching its elastic limit, the relative slip between the sand and gravel caused new cracks in the cemented matrix, and the propagation degree and scale of the new cracks increased with the increase of load. In the cyclic loading-unloading test, the microcracks gradually formed and continued to develop during the loading stage, and the microcracks tended to be stable during the unloading stage and stopped at the complete unloading stage. With the continuous increase of load, the proportion of plastic deformation in the total deformation of loaded sandstone increased gradually. The propagation state of microcracks began to change, and the stress concentration at the crack tip constantly appeared, which led to the derivation of new cracks. The secondary cracks developed into new cracks and merged with other cracks until the main cracks gradually formed, and the transverse deformation of the specimen occurred, and the volume of the rock expanded. (4) Failure stage: after the loading stress rose to the peak strength, the rock appeared macrofailure, the surface was obvious through cracks, and the sandstone was crushed as a whole.

It can be seen from Figure 4 that there is no obvious difference in the overall trend of the stress-strain curve of sandstone under cyclic loading of different upper limit stress. However, with the increase of the upper-stress limit, the shift of the hysteresis loop to the axial strain becomes more and more obvious, which is due to the plastic deformation caused by the initial crack in the specimen being compressed and closed. 


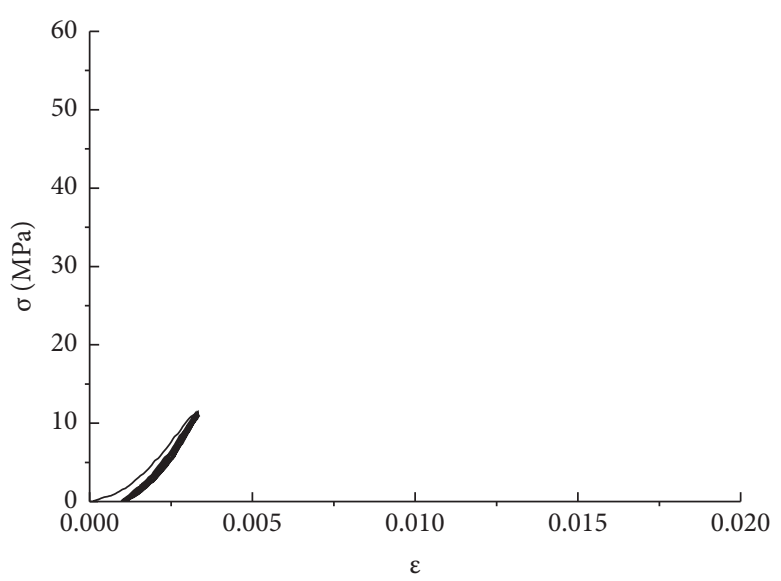

(a)

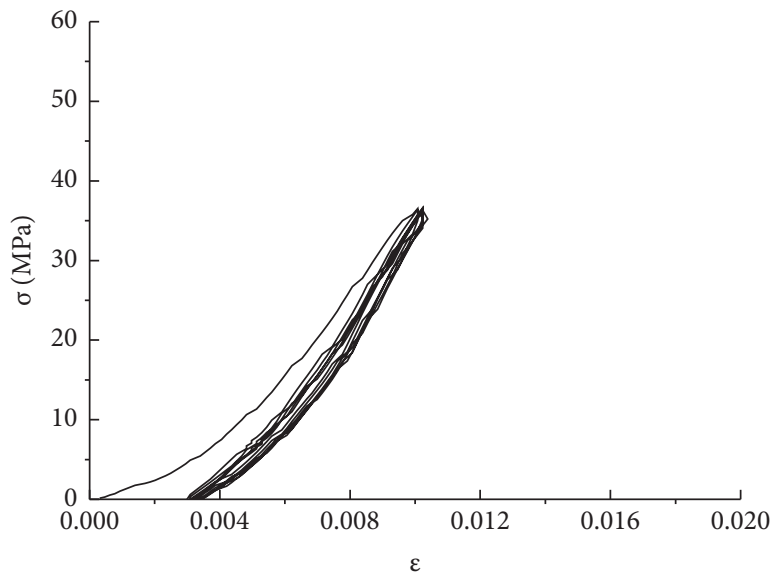

(c)

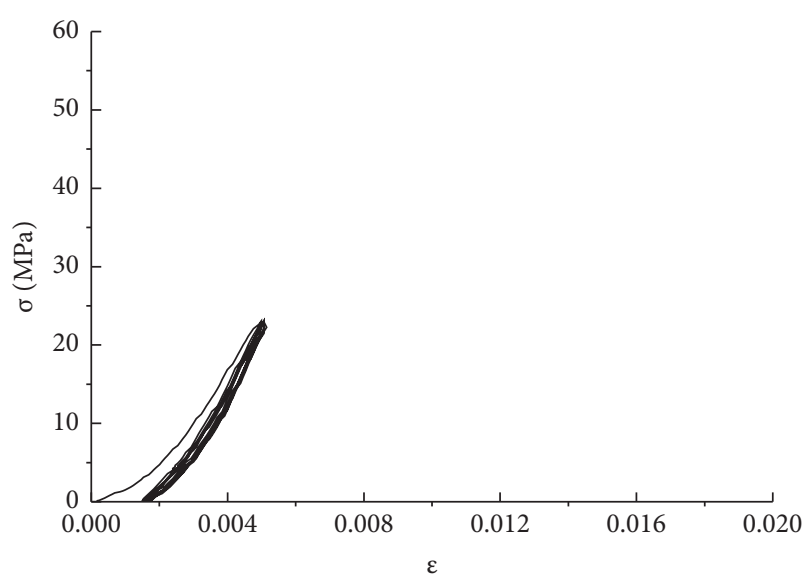

(b)

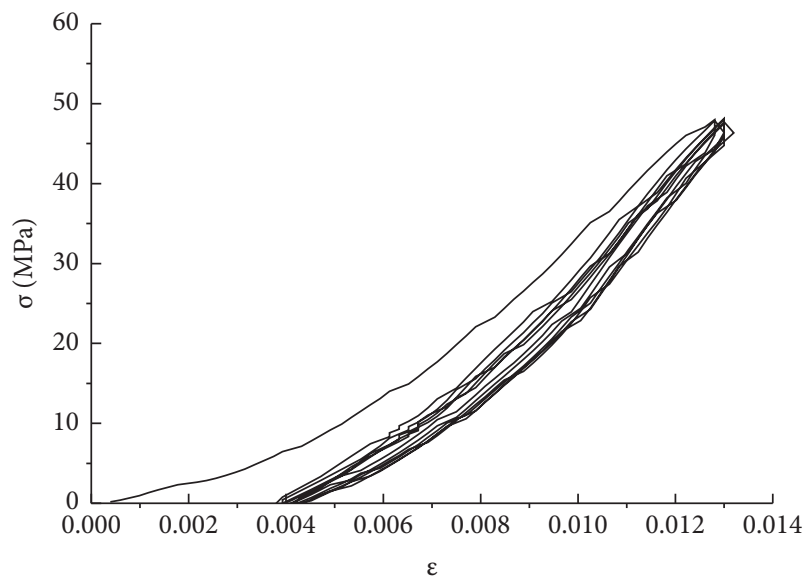

(d)

FIgURE 4: Stress-strain curves of sandstone under cyclic loading with different upper limits of stresses.

3.1. Compressive Strength of Damaged Sandstone. Previously, the mechanism of meso change of sandstone under load was analyzed. Cyclic loading-unloading tests were carried out on sandstone with different upper-stress limits. The strength of sandstone with different damage degrees would inevitably change. A uniaxial loading test was carried out on sandstone with different damage degrees after cyclic loading-unloading, and the uniaxial compressive strength of damaged sandstone was determined, as shown in Table 1.

According to the test results in Table 1, with the increase of the upper limit of stress, the uniaxial compressive strength of damaged sandstone decreases gradually. It can also be found from Figure 4 that the plastic deformation of sandstone is different after cyclic loading with different upper limits of stress. In order to more comprehensively grasp the strength change and deformation characteristics of damaged sandstone after cyclic loading-unloading, the upper limit of stress is fitted with the plastic deformation and strength of sandstone after cyclic loading-unloading, as shown in Figures 5 and 6 .

It can be seen from the test results in Figures 5 and 6 that with the increase of the upper-stress limit, the uniaxial compressive strength of the damaged sandstone gradually decreases, and the plastic deformation gradually increases, and the reduction rate of uniaxial compressive strength and the growth rate of plastic deformation gradually increase. With the increase of the upper-stress limit, the deterioration degree of the internal microstructure of sandstone gradually increases, and the deterioration rate also increases with the increase of the upper-stress limit.

3.2. Change of Elastic Modulus. In order to quantitatively describe the elastic deformation characteristics of sandstone under cyclic loading-unloading, this paper analyzes the changes of elastic modulus in different loading-unloading stages. The stress-strain curve of the cyclic loadingunloading test is more complicated than the stress-strain curve of the uniaxial loading test. Therefore, the elastic modulus of the loading stage and the unloading stage are usually calculated separately. The elastic modulus value of each segment is shown in Table 2 , and the calculated elastic modulus is fitted with the number of cycles, as shown in Figure 7.

It can be seen from the test results in Table 2 and Figure 7 that in the cyclic loading-unloading test, the elastic modulus of damaged sandstone gradually increases with the increase 
TABLE 1: Uniaxial compressive strength of sandstone with different damage degrees.

\begin{tabular}{|c|c|c|}
\hline Number & Strength $(\mathrm{MPa})$ & Average strength (MPa) \\
\hline $0.2-1$ & 59.13 & \\
\hline $0.2-2$ & 52.98 & 57.62 \\
\hline $0.2-3$ & 60.75 & \\
\hline $0.4-1$ & 57.65 & \\
\hline $0.4-2$ & 54.12 & 56.03 \\
\hline $0.4-3$ & 56.34 & \\
\hline $0.6-1$ & 41.66 & \\
\hline $0.6-2$ & 45.22 & 44.68 \\
\hline $0.6-3$ & 47.18 & \\
\hline $0.8-1$ & 34.12 & \\
\hline $0.8-2$ & 21.95 & 26.03 \\
\hline $0.8-3$ & 22.01 & \\
\hline
\end{tabular}

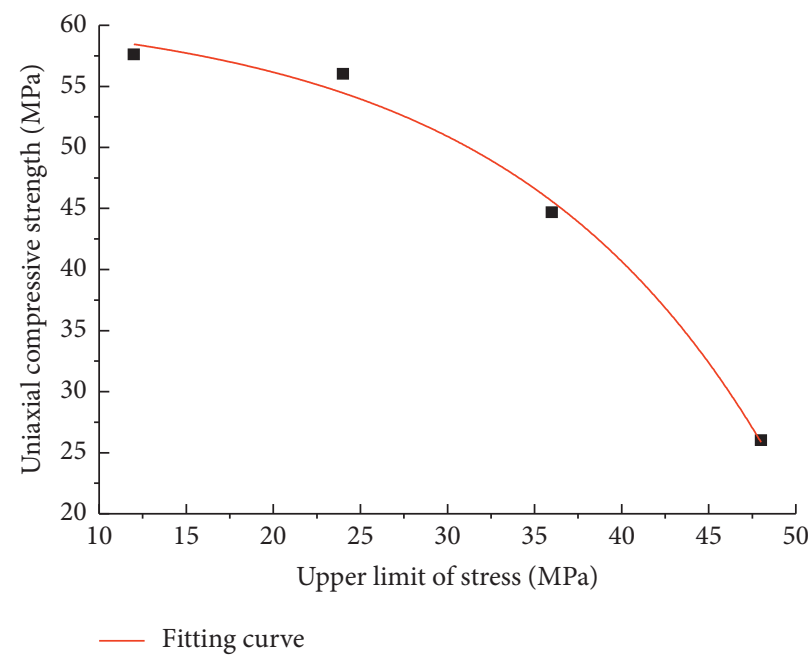

FIGURE 5: Uniaxial compressive strength of damaged sandstone under cyclic loading with different upper limits of stress.

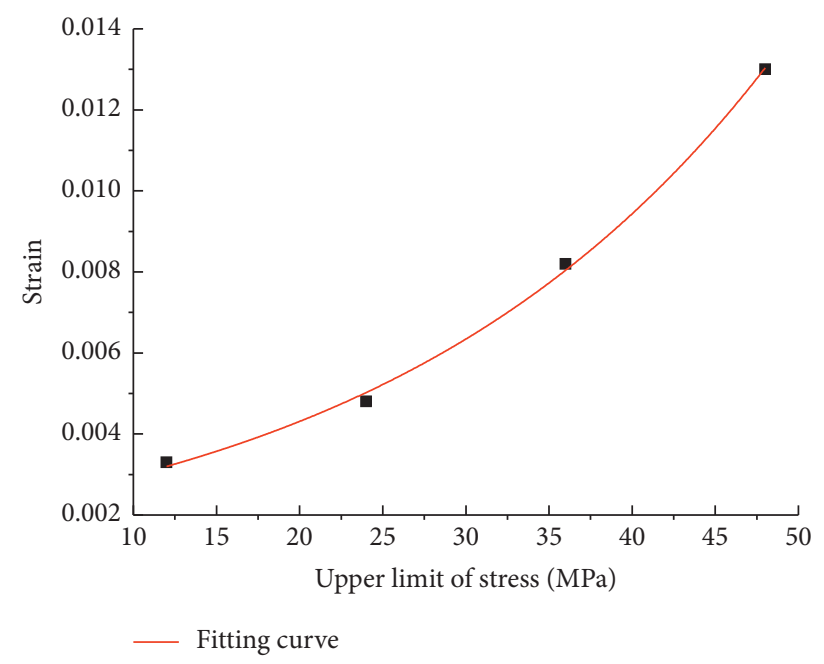

Figure 6: Plastic deformation of damaged sandstone under cyclic loading with different upper limits of stress.

of the number of cycles, but the increasing rate gradually decreases and tends to be stable. In addition, it can be found that the elastic modulus of sandstone in the loading stage is smaller than that in the unloading stage. This shows that with the increase of the number of cycles, the damage in sandstone is gradually accumulated, and the damage degree is gradually reduced in each loading-unloading cycle. However, until the last cycle, the elastic modulus did not 
TAвLE 2: Elastic modulus of sandstone at different loading-unloading stages under different upper-stress limits (GPa).

\begin{tabular}{lcccccccc}
\hline \multirow{2}{*}{ Number of cycles } & \multicolumn{2}{c}{$0.2 \sigma$} & \multicolumn{2}{c}{$0.4 \sigma$} & \multicolumn{2}{c}{$0.6 \sigma$} & \multicolumn{2}{c}{$0.8 \sigma$} \\
& Load & Unload & Load & Unload & Load & Unload & Load & Unload \\
\hline 1 & 51.082 & 53.219 & 49.737 & 49.372 & 35.101 & 37.948 & 30.027 \\
2 & 59.650 & 64.351 & 56.236 & 60.512 & 43.241 & 47.657 & 37.427 & 40.989 \\
3 & 64.230 & 68.787 & 60.216 & 64.494 & 49.385 & 51.950 & 43.858 & 46.819 \\
4 & 67.269 & 72.369 & 62.540 & 66.102 & 51.401 & 54.535 & 47.724 & 51.713 \\
5 & 69.298 & 73.672 & 63.984 & 70.396 & 54.412 & 56.406 & 50.737 \\
6 & 71.904 & 74.121 & 65.714 & 70.400 & 54.574 & 57.567 & 52.324 & 54.725 \\
\hline
\end{tabular}

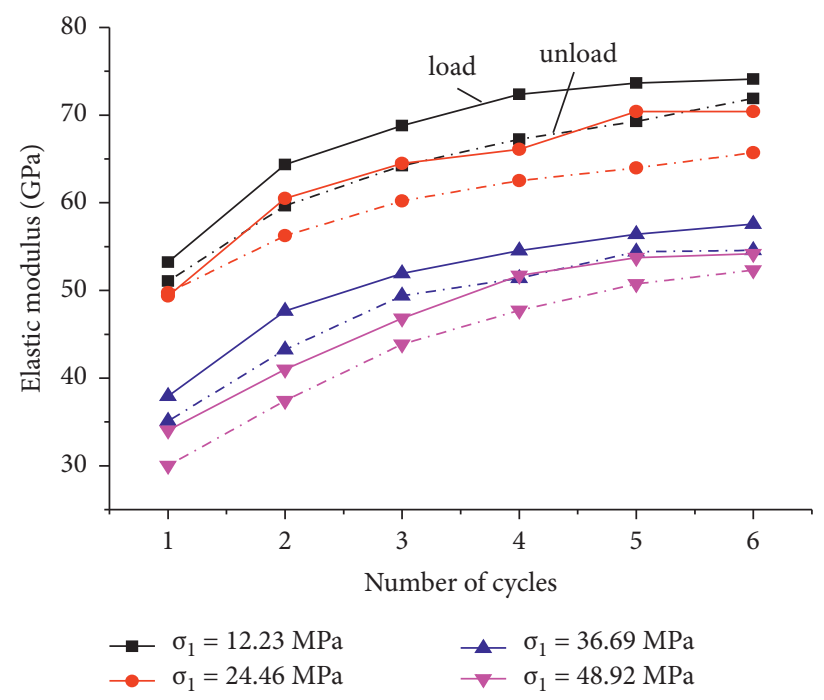

FIGURE 7: Variation of elastic modulus of sandstone in different loading-unloading stages under cyclic loading.

decrease. It also shows that the damage of sandstone under cyclic loading does not reach the fatigue failure limit of sandstone. Once the fatigue limit is reached, the sandstone specimen will fail. In addition, it can be seen that the elastic modulus of sandstone decreases with the increase of the upper limit of stress.

According to the mechanical properties of rock, the rock under load will deform due to resisting external force. The deformation includes the elastic deformation that can be recovered after unloading and the plastic deformation that cannot be recovered after the external force is removed. Before the elastic limit, the loaded rock is mainly elastic deformation. After that, it is mainly plastic deformation.

When the upper limit of stress was $0.2 \sigma$, the difference between the modulus of elasticity at the unloading stage and that at the loading stage increased with the increase of cycles. Because under a load of low stress, the primary pores in the sandstone were compacted and closed to a greater extent, resulting in the stiffness of the unloading section of the sandstone gradually increasing. When the upper limit of stress was greater than $0.2 \sigma$, the difference between the elastic modulus of the unloading stage and that of the loading stage became smaller due to the fact that the new cracks in sandstone expanded gradually and connected with each other.

The elastic modulus of sandstone was decreasing in both loading-unloading stages. When the upper limit of stress was small, the growth rate of elastic modulus gradually decreased with the increase of the upper-stress limit. When the upperstress limit gradually increased to a fixed value, the growth rate of elastic modulus approached 0 , and the curve began to stabilize.

According to the theory of rock mechanics, the change of elastic modulus of rock under cyclic loading could be divided into three stages. (1) The rising stage of elastic modulus: generally occurred at the initial stage of loading. At this time, the primary pores in the loaded rock were gradually compacted. In the subsequent unloading stage, some of the compacted primary pores were restored, but some of the closed fractures were not restored. Therefore, with the increase of rock stiffness, the elastic modulus also increased, but with the gradual increase of load, the new cracks began to expand, and the scale of cracks was also large, which cannot be restored after unloading. With the action of low-stress load, the effect of rock stiffness enhancement gradually weakened, resulting in the growth rate of elastic modulus gradually decreased. (2) Regional stability stage of elastic modulus: when the primary pores in the rock were compacted and closed, the loading continued, and the rock entered into the stage of nearly complete elastic deformation, and the elastic deformation gradually became stable. Under the influence of the tip effect of the gravel, the cemented matrix in some areas also began to crack. This kind of deformation could not be restored after the external force 
was removed, and the plastic deformation began to appear again in the loaded rock. At this time, the increasing trend of elastic modulus slowed down. (3) Elastic modulus decline stage: at the critical point of the previous stage, with the continued increase of stress, the cracks in the rock entered the stage of rapid expansion, and the damage degree of the rock was increasing. At this time, the scale and scope of fracture propagation were much larger than the previous two stages. At the same time, the plastic deformation of rock began to increase, so the elastic modulus decreased gradually.

3.3. Energy Evolution. The damage of sandstone under cyclic loading-unloading can be expressed by energy evolution in addition to strength change and plastic deformation. The energy method can quantitatively analyze the damage of sandstone and the deformation and failure of rock under cyclic loading-unloading, which is essentially the process of energy exchange between the internal and external rock. Rock failure is a process of instability caused by energy absorption, release, and transformation, and its principle is shown in Figure 8.

There are four main forms of energy transformation of sandstone under cyclic loading-unloading. (1) Energy input: since the beginning of loading, the loading device transmitted mechanical energy to the rock. At the same time, the friction between the loading end and the two ends of the rock specimen also generated a small amount of heat energy. These two kinds of energy were continuously input into the loaded rock during the loading process. (2) Energy accumulation and dissipation: the energy input from the outside accumulated in the rock, but not all of the energy was completely input into the rock, and some of the energy was dissipated. This dissipation effect was weak in the early stage of cyclic loading-unloading because the internal deterioration of sandstone was constantly strengthening, so with the increase of the number of cycles, more energy was dissipated. (3) Energy release: with the accumulation of internal damage in sandstone, the rock would be crushed, and the stored energy would be released in the form of kinetic energy.

Energy absorption and release were reversible, but energy dissipation could only be released from rock to the outside. In the cyclic loading-unloading test, the energy input from the outside made the rock elastic deformation in the loading stage and then released it to the outside in the unloading stage. In addition, the closure and expansion of fractures in rock would consume energy, which would reduce the total energy inside the rock, which led to the decrease of rock strength.

In the cyclic loading-unloading, the energy exchanged between sandstone and the outside was considered as dynamic conservation, and the energy redistribution was carried out continuously in the rock. The energy evolution and energy dissipation characteristics of sandstone during cyclic loading-unloading were studied. In order to facilitate calculation and analysis, the heat exchange in the whole test process was ignored as shown in the following equation:

$$
U=F L=U^{d}+U^{e},
$$

where $U$ is the total energy input by the loading system to the specimen, the total strain energy of the rock, $\mathrm{J} ; U^{d}$ is the dissipated energy of rock, J; $U^{e}$ is the elastic deformation energy of rock, J; $F$ is the load on the rock, $\mathrm{kN}$; and $L$ is the deformation of rock, $\mathrm{mm}$.

The absorbed energy of rock can be divided into two types. One type makes the rock plastic deformation and leads to the accumulation of internal damage, which can be called the dissipative energy of rock. The other is the recoverable deformation elastic deformation energy of rock, which is released continuously during unloading.

In order to eliminate the error caused by different input energy, this paper analyzes the energy evolution of rock under cyclic loading-unloading by means of energy proportion, as shown in

$$
\begin{aligned}
& E_{d}=\frac{U^{d}}{U}, \\
& E_{s}=\frac{U^{e}}{U},
\end{aligned}
$$

where $E_{d}$ is the energy dissipation rate, which means the proportion of the rock dissipative energy in the total absorption energy, \%. $E_{s}$ is the energy storage rate, which is the proportion of elastic deformation energy of rock in the total absorbed energy, \%.

The calculated energy ratio of sandstone under cyclic loading-unloading is shown in Table 3. At the same time, the energy dissipation rate and energy storage rate of sandstone with different damage degrees at different loading-unloading stages are fitted, as shown in Figures 9 and 10, respectively. In addition, the total deformation energy density, elastic energy density, and dissipated energy density of sandstone with different damage degrees at different loading-unloading stages are fitted, as shown in Figures 11-13.

According to the test results in Figures 9 and 10, when the upper limit of stress is not greater than $0.4 \sigma$, the energy dissipation rate decreases and the energy storage rate increases with the increase of cycle times. When the upper limit of stress is greater than $0.4 \sigma$, the energy dissipation first decreases and then increases with the increase of the number of cycles, while the change of energy storage rate is opposite to that of the energy dissipation rate.

When the upper limit of stress is $0.2 \sigma$, the energy storage rate increases to $75.71 \%$ with the increase of cycles, combined with the above analysis of deformation mechanism, it can be seen that under the load of the upper limit of stress, the deformation in sandstone is mainly the primary pores are compacted and closed, and the closure of fractures leads to the continuous absorption of strain energy. In the initial loading stage, the plastic deformation of sandstone is large, and the absorbed energy is stored in the sandstone in the form of elastic deformation energy. But in the local space of rock with lower strength, the energy is dissipated, and the proportion of dissipated energy decreases with the increase of cycles. It shows that 


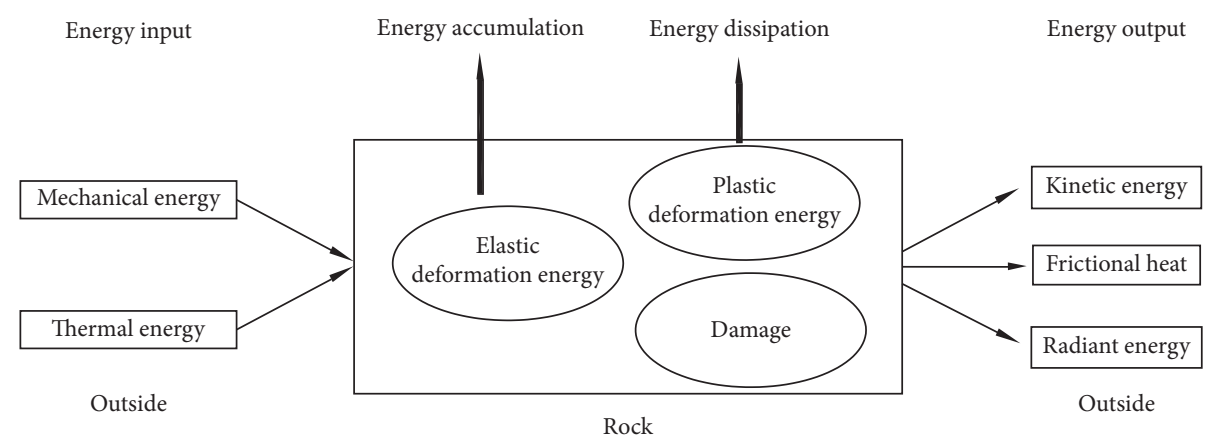

FIGURE 8: Energy transformation diagram of rock and external environment.

TABle 3: Proportion of different kinds of energy in sandstone under cyclic loading-unloading (\%).

\begin{tabular}{lcccccccc}
\hline \multirow{2}{*}{ Number of cycles } & \multicolumn{2}{c}{$0.2 \sigma$} & \multicolumn{2}{c}{$0.4 \sigma$} & \multicolumn{2}{c}{$0.6 \sigma$} & & \\
& $E_{d}$ & $E_{s}$ & $E_{d}$ & $E_{s}$ & $E_{d}$ & $E_{s}$ & $E_{d}$ \\
\hline 1 & 69.41 & 30.59 & 67.33 & 32.67 & 68.80 & 31.20 & 64.64 \\
2 & 60.29 & 39.71 & 58.41 & 41.59 & 46.48 & 53.52 & 33.24 \\
3 & 48.33 & 51.67 & 49.83 & 50.17 & 27.47 & 72.53 & 30.94 & 66.76 \\
4 & 37.81 & 62.19 & 40.32 & 59.68 & 29.63 & 70.37 & 34.63 \\
5 & 24.29 & 75.71 & 34.33 & 65.67 & 33.70 & 66.30 & 44.80 \\
\hline
\end{tabular}

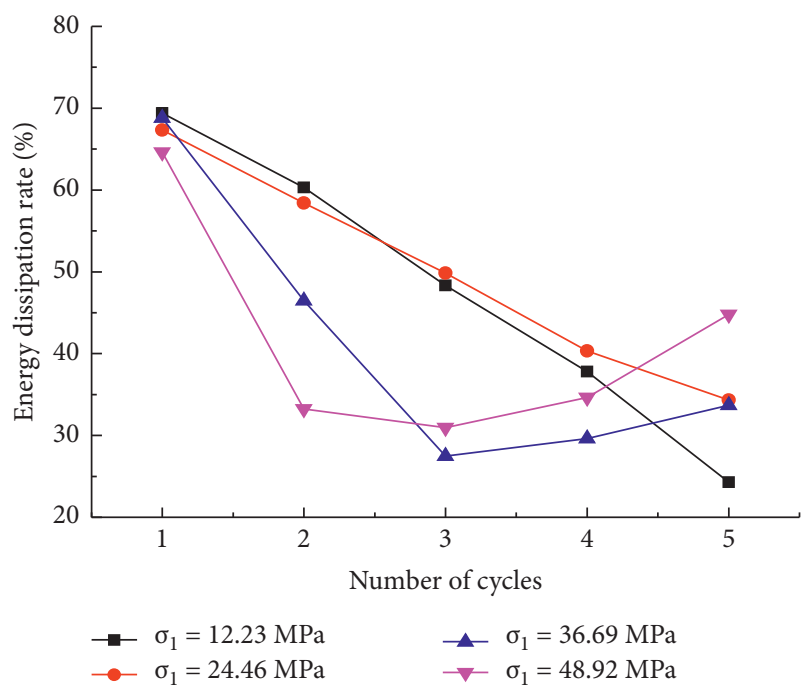

FIGURE 9: Energy dissipation rate of sandstone with different damage degrees at different loading-unloading stages.

the damage fracture in the rock does not expand in a large range, and the rock is mainly in the stage of initial crack subclosed.

When the upper limit of stress is $0.4 \sigma$, the changing trend of energy storage rate is the same as that of the upper limit of stress is $0.2 \sigma$, which is in a linear rising state. However, in the fifth cycle, the increasing rate decreases compared with the previous cycles, which indicates that the storage of elastic deformation energy in rock tends to be stable gradually, while the growth rate of dissipated energy increases. Combined with the mechanical mechanism of the loaded rock, it can be seen that under the action of tip effect, the cemented matrix begins to crack.

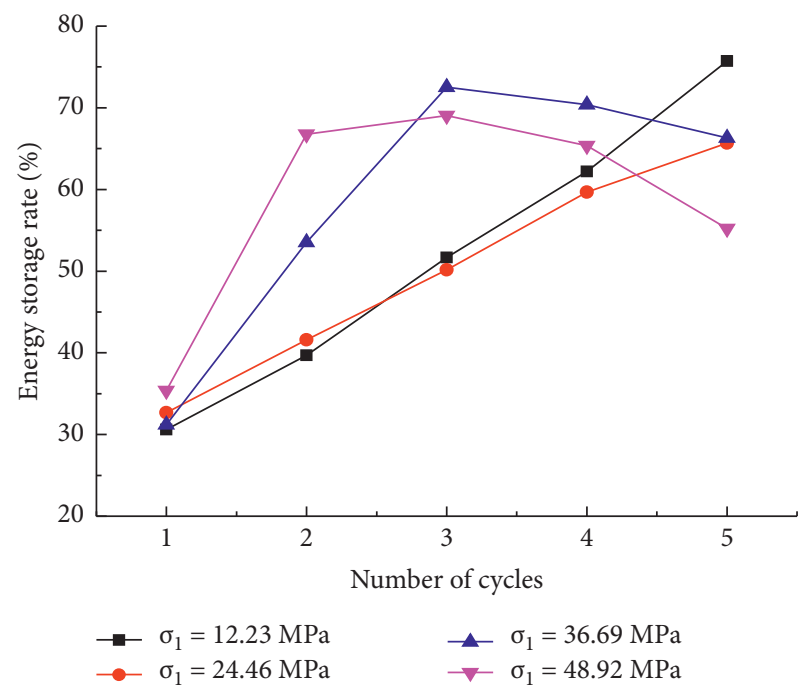

FIGURE 10: Energy storage rate of sandstone with different damage degrees at different loading-unloading stages.

When the upper limit of stress is $0.6 \sigma$, the growth part of energy storage energy ends in the third cycle. In the fourth and fifth cycles, the elastic deformation energy of sandstone begins to decrease, and most of its absorbed energy turns into dissipative energy. This is due to the continuous propagation of cracks in the rock and the irrecoverable plastic deformation in the rock. Within this range, the deformation growth rate of rock slows down.

When the upper limit of stress is $0.8 \sigma$, the fracture compaction section of sandstone basically ends in the first cycle, and its energy storage capacity decreases to the lowest point in history, while the dissipated energy increases continuously. The continuous propagation of new cracks in 


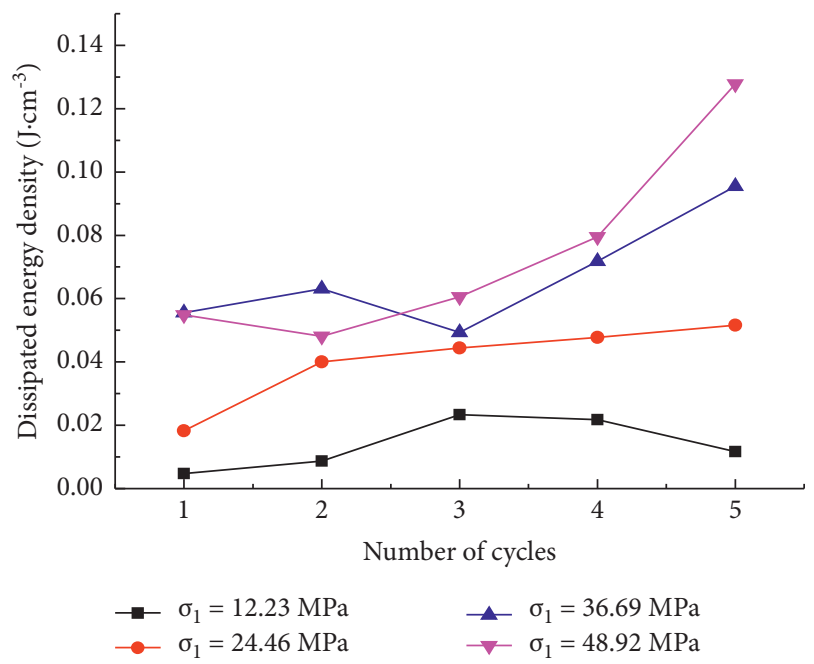

FIGURe 11: Dissipated energy density of sandstone with different damage degrees in different cycle stages.

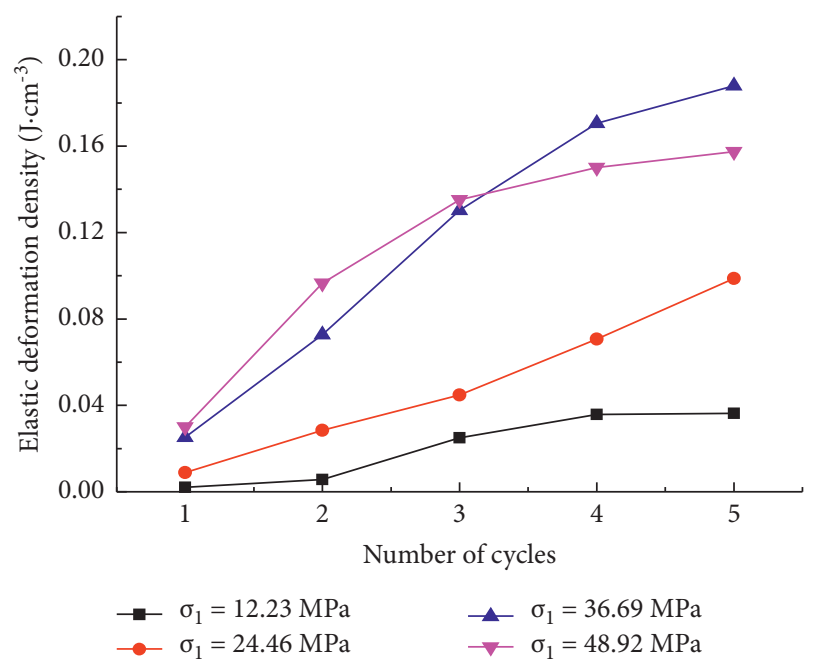

FIGURE 12: Elastic energy density of sandstone with different damage degrees in different cycle stages.

the rock leads to a significant increase in plastic deformation. The new cracks propagate rapidly in the rock and induce secondary cracks, which leads to the strength reduction of sandstone. In the accelerated damage stage, each energy ratio curve will show inflection point, and the surface rock failure stage will appear. But from the overall change trend in the figure, the energy storage rate is still in the stable decline stage, and the overall failure crushing of rock samples does not appear.

It can be seen from the test results in Figures 11-13 that the total strain energy, elastic deformation energy, and dissipated energy of loaded sandstone gradually increase with the increase of cycle times. This is because the internal damage of sandstone under cyclic loading-unloading gradually accumulates, resulting in the increase of total strain energy. With the increase of load, the elastic deformation of sandstone increases. Therefore, the elastic deformation energy of loaded sandstone increases gradually.

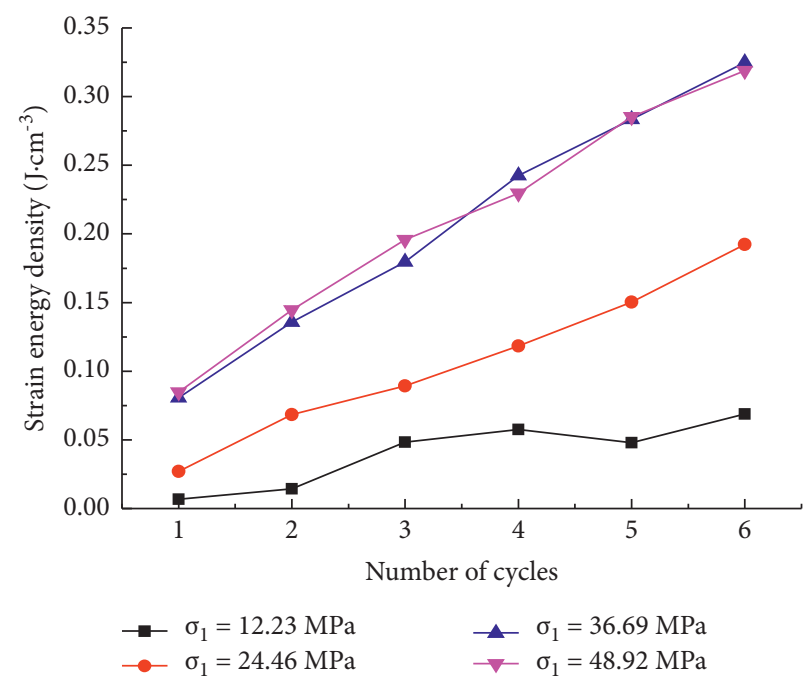

FIGURE 13: Strain energy density of sandstone with different damage degrees in different cycle stages.

Under cyclic loading with a different upper limit of stress, the dissipated energy increases with the increase of cyclic times. When the upper-stress limit is $0.2 \sigma$, the dissipative energy increases slowly in the first three loading-unloading cycles and decreases slightly in all loading-unloading cycles from the fourth cycle to the end of the test. When the upper limit of stress is $0.4 \sigma, 0.6 \sigma$, and $0.8 \sigma$, the dissipated energy is positively correlated with the number of cycles, and the growth rate of dissipated energy decreases with the increase of the upper limit of stress. This is because the damage in the loaded rock increases with the increase of the upper limit of stress.

When the upper limit of stress is $0.2 \sigma$ and $0.4 \sigma$, the dissipative energy of loaded sandstone is lower, which is because, under the cyclic loading-unloading of low stress, the cracks inside the loaded rock are repeatedly compacted and closed. When the upper limit of stress increases to $0.6 \sigma$ and $0.8 \sigma$, the dissipated energy in the loaded sandstone increases rapidly. This is because the plastic deformation in sandstone is significantly increased compared with the upper limit of $0.2 \sigma$ and $0.4 \sigma$, and the damage degree of loaded rock is significantly greater than that of sandstone under cyclic loading with a low upper limit of stress.

It can be seen from the test results in Figures 12 and 13 that the elastic deformation energy density and total strain energy density of loaded sandstone increase with the increase of cycle times, showing a nearly linear growth trend.

When the upper limit of stress is $0.2 \sigma$, the elastic deformation energy density, the dissipated energy density, and the total strain energy density are the minimum compared with other upper limits of stress. In the first two loadingunloading cycles, the dissipated energy density is greater than the elastic deformation energy density, but in the next three loading-unloading cycles, the elastic deformation energy density is greater than the dissipated energy density.

When the upper limit of stress is $0.4 \sigma$, compared with the upper limit of stress is $0.2 \sigma$, the elastic deformation energy density, the dissipated energy density, and the total strain 
TABle 4: Dissipation energy of sandstone with different damage degrees under impact load $(\mathrm{J})$.

\begin{tabular}{lcccc}
\hline Upper limit of stress & $0.2 \sigma$ & $0.4 \sigma$ & $0.6 \sigma$ & $0.8 \sigma$ \\
Total dissipated energy & 0.0702 & 0.2019 & 0.3353 & 0.3707 \\
\hline
\end{tabular}

TABLE 5: Damage factors of sandstone under cyclic loading with different upper limits of stress.

\begin{tabular}{lcccc}
\hline Upper limit of stress & $0.2 \sigma$ & $0.4 \sigma$ & $0.6 \sigma$ & $0.8 \sigma$ \\
Damage factor & 0.1894 & 0.5446 & 0.9045 & 1 \\
\hline
\end{tabular}

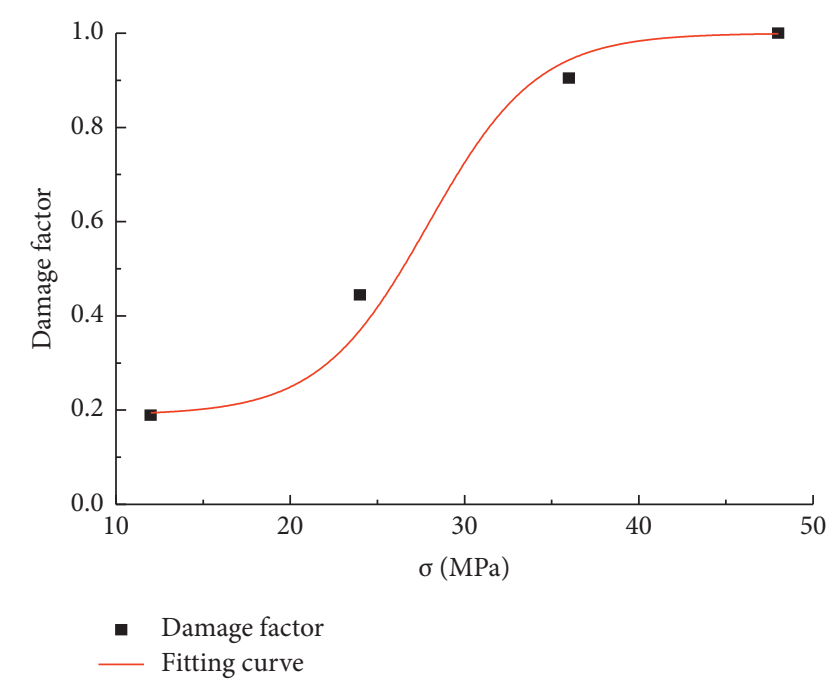

Figure 14: Damage factors of sandstone under cyclic loading with different upper limits of stress.

energy density all increase with the increase of the number of cycles, but the growth rate gradually decreases. The reason is that under the cyclic loading-unloading action of the upperstress limit, some cracks and primary pores are still compacted and closed, while the elastic deformation energy density decreases in the fourth and fifth cyclic stages.

When the upper limit of stress is $0.6 \sigma$ and $0.8 \sigma$, the elastic deformation energy density is close to the total strain energy density, and both are larger than the former both.

\subsection{Analysis of Damage Evolution Based on Energy} Dissipation. In the cyclic loading-unloading test of sandstone, the energy dissipation is caused by the accumulation of damage in the rock. Therefore, it is reasonable to define sandstone damage by dissipative energy density. With the increase of the number of cycles, the dissipative energy density of the loaded sandstone is also increasing, as shown in Table 4.

In this paper, it is assumed that the damage of sandstone under cyclic loading-unloading with the upper limit of the stress of $0.8 \sigma$ is 1 , and the damage of loaded rock is characterized by the energy method, as shown in the following equation:

$$
D^{\prime}=\frac{\sum U^{e}}{\sum_{0.8 \sigma} U^{e}},
$$

where $D^{\prime}$ is the damage factor; $\sum U^{e}$ is the sum of dissipated energy during cyclic loading-unloading, J; and $\sum_{0.8 \sigma} U^{e}$ is the sum of dissipated energy when the upper limit of stress is $0.8 \sigma, \mathrm{J}$.

The damage factors of loaded sandstone under cyclic loading with different upper limits of stress are calculated, as shown in Table 5 . In addition, the calculated damage factors are fitted, as shown in Figure 14.

Based on the damage degree represented by the dissipated energy of loaded sandstone, it can be seen that the damage degree of sandstone under cyclic loading-unloading increases with the increase of the upper limit of stress, and increases slowly at first, then increases rapidly, and finally tends to be stable, showing an S-shaped growth.

\section{Conclusions}

In this paper, cyclic loading-unloading with different upperstress limits is applied to the sandstone specimens to make them in different degrees of damage. Then, based on the strength change, plastic deformation and energy evolution of the damaged sandstone, the change law of damage degree of sandstone with the increase of upper-stress limit is analyzed. The results are as follows:

(1) The plastic deformation and damage degree of sandstone under cyclic loading-unloading with different upper-stress limits increase with the increase of upper-stress limit. The strength of sandstone under cyclic loading-unloading decreases with the increase of upper-stress limit, and the reduction rate also increases with the increase of upper-stress limit.

(2) In general, the elastic modulus of the loading section and unloading section increase with the increase of cycle times. When the upper limit of stress is low, the elastic modulus goes through the rising stage and regional stability stage, while when the upper limit of stress is high, the elastic modulus will appear in the declining stage at last.

(3) When the upper limit of stress is less than $0.4 \sigma$, the energy dissipation rate decreases and the energy storage rate increases with the increase of the number of cycles. When the upper limit of stress is greater than $0.4 \sigma$, the energy dissipation first decreases and then increases with the increase of the number of cycles, while the change of energy storage rate is opposite to that of the energy dissipation rate.

(4) The total strain energy density and elastic deformation energy density increase with the increase of the number of cycles. In general, both of them increase with the increase of the upper limit of stress.

(5) The damage factor of sandstone after cyclic loadingunloading based on dissipated energy increases in S-shape with the increase of upper-stress limit, and the increase first increases and then decreases. 


\section{Data Availability}

The data used to support the findings of this study are available from the corresponding author upon request.

\section{Conflicts of Interest}

The authors declare no conflicts of interest regarding the publication of this paper.

\section{Acknowledgments}

This work was funded by the Program in the Youth Elite Support Plan in Universities of Anhui Province (no. gxyq2020013) and Independent Research Fund of the State Key Laboratory of Mining Response and Disaster Prevention and Control in Deep Coal Mines (no. SKLMRDPC20ZZ06).

\section{References}

[1] X. S. Liu, J. G. Ning, Y. L. Tan, and Q. H. Gu, "Coordinated supporting method of gob-side entry retaining in coal mines and a case study with hard roof," Geomechanics and Engineering, vol. 15, no. 6, pp. 1173-1182, 2018.

[2] Q. Zheng, H. Hu, A. Yuan et al., "Impact dynamic properties and energy evolution of damaged sandstone based on cyclic loading threshold," Shock and Vibration, vol. 2020, Article ID 6615602, 12 pages, 2020.

[3] X. Wang and F.-b. Meng, "Statistical analysis of large accidents in China's coal mines in 2016," Natural Hazards, vol. 92, no. 1, pp. 311-325, 2018.

[4] J. Xu, G. Dai, W. Gong, Q. Haque, and R. P. Gamage, "A review of research on the shaft resistance of rock-socketed piles," Acta Geotechnica, vol. 16, no. 3, pp. 653-677, 2021.

[5] L. Gu, Z. Wang, Q. Huang, G. Ye, and F. Zhang, "Numerical investigate into ground treatment to mitigate the permanent train-induced deformation of pile-raft-soft soil system," Transportation Geotechnics, vol. 24, p. 11, Article ID 100368, 2020.

[6] Y. Xu, Q. Zheng, X. Gao, R. Yang, X. Ni, and Q. Wang, "Quantitative damage and fracture mode of sandstone under uniaxial load based on acoustic emission," Advances in Civil Engineering, vol. 2020, Article ID 6685795, 9 pages, 2020.

[7] X. Zhang, Y. Jiang, G. Wang, Y. Cai, and T. Iura, "Threedimensional seismic performance of mountain tunnel with imperfect interface considering $\mathrm{P}$ wave," Tunnelling and Underground Space Technology, vol. 39, p. 12, Article ID 103720, 2021.

[8] Q.-q Zheng, Y. Xu, H. Hu, J.-w Qian, Q. Zong, and P. Xie, "Fracture and tomography of velocity structures of sandstone under uniaxial loads," Chinese Journal of Geotechnical Engineering, vol. 43, no. 6, pp. 1069-1077, 2021.

[9] X. Zhang, Y. Jiang, Y. Cai, and S. Sugimoto, “Anti-plane seismic performance of a shallow-buried tunnel with imperfect interface in anisotropic half-space," Tunnelling and Underground Space Technology, vol. 112, p. 15, Article ID 103906, 2021.

[10] X. Wang, N. Wu, H. Li, and Y. Yan, "Influence of joint angle on the instability failure characteristics and AE evolution law of underground caverns," European Journal of Environmental and Civil Engineering, vol. 39, no. 5, pp. 3437-3447, 2020.

[11] F.-q. Gong, Y. Luo, X.-b. Li, X.-f. Si, and M. Tao, "Experimental simulation investigation on rockburst induced by spalling failure in deep circular tunnels," Tunnelling and Underground Space Technology, vol. 81, pp. 413-427, 2018.

[12] X. Wu, Y. Jiang, B. Gong, Z. Guan, and T. Deng, "Shear performance of rock joint reinforced by fully encapsulated rock bolt under cyclic loading condition," Rock Mechanics and Rock Engineering, vol. 52, no. 8, pp. 2681-2690, 2019.

[13] Q. Zheng, Y. Xu, H. Hu, J. Qian, Y. Ma, and X. Gao, "Quantitative damage, fracture mechanism and velocity structure tomography of sandstone under uniaxial load based on acoustic emission monitoring technology," Construction and Building Materials, vol. 272, p. 13, Article ID 121911, 2021.

[14] X. Li, Z. Li, E. Wang et al., "Pattern recognition of mine microseismic (MS) and blasting events based on wave fractal features," Fractals, vol. 26, no. 3, Article ID 1850029, 2018.

[15] C. Wang, B. He, X. Hou, J. Li, and L. Liu, "Stress-energy mechanism for rock failure evolution based on damage mechanics in hard rock," Rock Mechanics and Rock Engineering, vol. 53, no. 3, pp. 1021-1037, 2020.

[16] F. Rui and G. Zhao, "Experimental and numerical investigation of laser-induced rock damage and the implications for laser-assisted rock cutting," International Journal of Rock Mechanics and Mining Sciences, vol. 139, Article ID 104653, 2021.

[17] Y. Li, D. Jia, Z. Rui, J. Peng, C. Fu, and J. Zhang, "Evaluation method of rock brittleness based on statistical constitutive relations for rock damage," Journal of Petroleum Science and Engineering, vol. 153, pp. 123-132, 2017.

[18] V. Srinivasan, T. Gupta, T. A. Ansari, and T. N. Singh, "An experimental study on rock damage and its influence in rock stress memory in a metamorphic rock," Bulletin of Engineering Geology and the Environment, vol. 79, no. 8, pp. 4335-4348, 2020.

[19] Q. Zheng, Y. Cheng, Q. Zong, Y. Xu, F. Li, and P. Chen, "Failure mechanism of different types of shotcrete based on modified Weibull distribution model," Construction and Building Materials, vol. 224, pp. 306-316, 2019.

[20] J. Wang, J. G. Ning, P. Q. Qiu, S. Yang, and H. F. Shang, "Microseismic monitoring and its precursory parameter of hard roof collapse in longwall faces: a case study," Geomechanics and Engineering, vol. 17, no. 4, pp. 375-383, 2019.

[21] L. Li, I. Larsen, and R. M. Holt, "Laboratory observation and micromechanics-based modelling of sandstone on different scales," Rock Mechanics and Rock Engineering, vol. 48, no. 4, pp. 1407-1422, 2015.

[22] M. Ghamgosar, N. Erarslan, and D. J. Williams, "Experimental investigation of fracture process zone in rocks damaged under cyclic loadings," Experimental Mechanics, vol. 57, no. 1, pp. 97-113, 2017.

[23] Q.-b. Meng, J.-F. Liu, L. Ren, H. Pu, and Y.-1. Chen, "Experimental study on rock strength and deformation characteristics under t cyclic loading and unloading conditions," Rock Mechanics and Rock Engineering, vol. 54, no. 2, pp. 777-797, 2021.

[24] L. Zhong, H. Wang, X. Ren, and L. Tang, "Influence of the cyclic loading path on rock deformation memory effect," Geofluids, vol. 2020, Article ID 8896344, 14 pages, 2020.

[25] S. Ma, C. He, Z. Zhao, W. Nie, X. Zhu, and Z. Zhang, "Modeling of rock joints under cyclic loading conditions using discontinuous deformation analysis," Rock Mechanics and Rock Engineering, vol. 50, no. 5, pp. 1205-1215, 2017.

[26] S. Song, X. Liu, Y. Tan, D. Fan, Q. Ma, and H. Wang, "Study on failure modes and energy evolution of coal-rock combination under cyclic loading," Shock and Vibration, vol. 2020, Article ID 5731721, 16 pages, 2020. 
[27] X. S. Liu, J. G. Ning, Y. L. Tan, and Q. H. Gu, "Damage constitutive model based on energy dissipation for intact rock subjected to cyclic loading," International Journal of Rock Mechanics and Mining Sciences, vol. 85, pp. 27-32, 2016.

[28] G. Tiwari and G. M. Latha, "Reliability analysis of jointed rock slope considering uncertainty in peak and residual strength parameters," Bulletin of Engineering Geology and the Environment, vol. 78, no. 2, pp. 913-930, 2019.

[29] M. A. Lotidis, P. P. Nomikos, and A. I. Sofianos, "Numerical study of the fracturing process in marble and plaster hollow plate specimens subjected to uniaxial compression," Rock Mechanics and Rock Engineering, vol. 52, no. 11, pp. 43614386, 2019.

[30] S. Yin, D. Li, X. Yang, and R. Wang, "Experimental investigation of the petrophysical properties, minerals, elements and pore structures in tight sandstones," Journal of Natural Gas Science and Engineering, vol. 76, Article ID 103189, 2020.

[31] T. Li, X. Pei, D. Wang, R. Huang, and H. Tang, "Nonlinear behavior and damage model for fractured rock under cyclic loading based on energy dissipation principle," Engineering Fracture Mechanics, vol. 206, pp. 330-341, 2019.

[32] F. Marinelli and G. Buscarnera, "Anisotropic breakage mechanics: from stored energy to yielding in transversely isotropic granular rocks," Journal of the Mechanics and Physics of Solids, vol. 129, no. 8, pp. 1-18, 2019.

[33] C. Ai, J. Zhang, Y.-w. Li, J. Zeng, X.-l. Yang, and J.-g. Wang, "Estimation criteria for rock brittleness based on energy analysis during the rupturing process," Rock Mechanics and Rock Engineering, vol. 49, no. 12, pp. 4681-4698, 2016.

[34] Y. Luo, F.-q. Gong, X.-b. Li, and S.-y. Wang, "Experimental simulation investigation of influence of depth on spalling characteristics in circular hard rock tunnel," Journal of Central South University, vol. 27, no. 3, pp. 891-910, 2020. 